УДК 387.147

\title{
ОПЫТ ИСПОЛЬЗОВАНИЯ ZООМ В ОБРАЗОВАТЕЛЬНОМ ПРОЦЕССЕ В ИРИТ НГТУ ИМ. Р.Е. АЛЕКСЕЕВА
}

\author{
Лазаревич Светлана Валерьевна \\ к.ф.н., доцент \\ НГТУ им. Р.Е.Алексеева
}

\begin{abstract}
Аннотация: В статье рассматриваются проблемы, с которыми столкнулись преподаватели кафедры «Иностранные языки» НГТУ им. Р.Е. Алексеева при использовании платформы zoom в процессе онлайн-обучения иностранным языкам. Проведено анкетирование студентов, обучающихся онлайн. Проведен анализ результатов указанного анкетирования.

Ключевые слова: онлайн-обучение, качество обучения, дистант, онлайн технологии.
\end{abstract}

\section{EXPERIENCE OF USING ZOOM IN THE EDUCATIONAL PROCESS AT IRIT NSTU NAMED AFTER R.E. ALEKSEEV}

\section{Lazarevich Svetlana Valerievna}

Abstract: The article discusses the problems the teachers of the department "Foreign languages" NSTU named after R.E. Alekseev faced when using the zoom platform in the process of online learning of foreign languages. A survey of online students was conducted. The analysis of the results of the specified questionnaire was carried out.

Key words: online training, quality of training, distance learning, online technologies.

В марте 2020 большинство студентов вузов РФ перешли на онлайнобучение. НГТУ им. Р.Е. Алексеева не был исключением. В нашем вузе для проведения практических занятий и зачетов/экзаменов преподаватели использовали такие платформы как skype, discord и zoom. В данной статье мы хотим показать те преимущества и недостатки, которые отметили 
студенты ИРИТ, а также показать трудности, с которыми столкнулись преподаватели НГТУ при использовании онлайн платформ.

Под онлайн-обучением мы понимаем «способ организации учебного процесса с использованием образовательной среды, основанной на интернет технологиях, обучение с помощью сети Интернет и мультимедиа» [1]. Возможность онлайн-обучения была признана в Европе и США много лет назад. В России это признание прошло много позже. Однако, следует отметить, что в России некоторые коммерческие и государственные вузы активно внедряли онлайн технологии начиная с 1990 годов. Одни вузы были успешны в этом, другие имели печальный опыт. Экстренный переход большинства вузов на дистант весной 2020 года значительно отличался от тщательно продуманного и спланированного курса. Надо отметить и разную готовность вузов к переходу на онлайн-обучение. НГТУ предоставил возможность преподавателям при необходимости проводить занятия из компьютерных классов, аудиторий кафедры и методических кабинетов. Кроме того, преподаватели могли воспользоваться платной версией платформы zoom, которую предоставлял университет. Конечно, численность штатных работников технического персонала, готовых оказать помощь в использовании онлайн платформ, оказалась небольшой, но и количество преподавателей, нуждавшихся в такой поддержке было меньше, чем мы предполагали. Сейчас активно ведутся дискуссии о преимуществах и недостатках онлайн-обучения и хотелось бы, чтобы полученный опыт способствовал улучшению качества онлайн-обучения и позволил бы большинству преподавателей использовать преимущества онлайн-обучения в будущем. Большинство преподавателей считают, что качество обучения значительно падает при онлайн-обучения. По нашему мнению, уровень онлайн-обучения магистров в нашем вузе, в частности в ИРИТ не только остался прежним, а даже стал выше. Использование платформы зум при проведений практических занятий по английскому языку привело к практически стопроцентной посещаемости занятий студентами, что не было отмечено на традиционных занятиях. Студенты могли присутствовать на онлайн занятиях даже будучи больными, не боясь заразить своих одногруппников или преподавателей. Работающие студенты присутствовали на занятиях и из своих офисов, некоторые посещали своих родителей и выходили на связь из домов своих родителей. Барьер места и времени был преодолен. Изменились формы и способы коммуникации преподавателей и 
студентов. Наши преподаватели были не готовы к переходу на такой тип обучения, они изучали возможности онлайн платформы вместе со студентами. Мотивированные студенты узнавали возможности платформы зум и делились своим знаниями со своими преподавателями. В форсмажорных обстоятельствах наши молодые преподаватели активно помогали более возрастным коллегам внедрить те или иные возможности платформы зум процесс обучения. Конечно, более детальное обучение всего профессорско-преподавательского состава требовало более длительного времени, а условия пандемии требовали немедленного перехода на онлайн. По нашему мнению, требуется два-три года для обучения всего профессорско-преподавательского состава максимально эффективно использовать те преимущества, которые предоставляет онлайн-обучение. Оценка эффективности онлайн-обучения будет сделана позже через призму различных целевых показателей. Традиционная модель обучения будет переосмыслена, появятся новые курсы онлайн-обучения.

Преподаватели английского языка, работавшие с магистрантами ИРИТ, использовали платформу зум для проведения практических занятий. Экзаменационная сессия также прошла при помощи этой платформы. Студенты включали камеры и использовали демонстрацию экрана для презентаций по темам «Мой университет», «Мой институт», «Моя научная работа». Для устных ответов по пройденному материалу использовались сессионные залы. Мы использовали сессионные залы и для составления диалогов студентами, обсуждения заданий в ролевых играх, которые требовали деления студентов на микрогруппы. Некоторые преподаватели использовали зум для групповых проектов. Ограничение в 40 минут значительно усложняло работу, так как после перерыва тратилось время на повторное подключение и иногда интернет «подвисал». Когда были значительные проблемы с подключением, приходилось выключать камеры и преподаватели разговаривали с «пустотой», однако это не вызывало значительного дискомфорта. Студенты ИРИТ имеют гораздо больший опыт общения с компьютером, нежели студенты других институтов НГТУ. Мы провели небольшой опрос магистрантов ИРИТ с целью выяснить их удовлетворенность онлайн-обучением и для того, чтобы оценить перспективы использования смешанного обучения в нашем вузе. В опросе приняли участие 78 студентов. 
Таблица 1

\begin{tabular}{|l|c|c|c|}
\hline \multicolumn{1}{|c|}{ Вопрос } & Да & Нет & $\begin{array}{c}\text { Затрудняюсь } \\
\text { ответить }\end{array}$ \\
\hline $\begin{array}{l}\text { 1. Использовали ли платформу зум до } \\
\text { перехода на онлайн-обучение? }\end{array}$ & $63 \%$ & $37 \%$ & $0 \%$ \\
\hline $\begin{array}{l}\text { 2. Лучше ли Вы усваивали материал при } \\
\text { традиционном обучении? }\end{array}$ & $43 \%$ & $33 \%$ & $24 \%$ \\
\hline $\begin{array}{l}\text { 3. Испытывали ли Вы дискомфорт, общаясь } \\
\text { онлайн? }\end{array}$ & $24 \%$ & $71 \%$ & $54 \%$ \\
\hline $\begin{array}{l}\text { 4. Важна ли Вам зрительная реакция } \\
\text { одногруппников и преподавателей при } \\
\text { Вашем ответе на поставленный на } \\
\text { занятии вопрос? }\end{array}$ & $41 \%$ & $36 \%$ & $23 \%$ \\
\hline $\begin{array}{l}\text { 5. Есть ли разница в усвоении онлайн } \\
\text { гуманитарных и технических дисциплин? }\end{array}$ & $49 \%$ & $48 \%$ & $13 \%$ \\
\hline $\begin{array}{l}\text { 6. Хотели бы Вы в дальнейшем } \\
\text { комбинировать онлайн-обучение и } \\
\text { традиционное обучение? }\end{array}$ & $44 \%$ & $31 \%$ & $15 \%$ \\
\hline
\end{tabular}

Как видно из таблицы (табл.1) большинство студентов были знакомы с платформой zoom до того, как они были переведены на онлайн-обучение. Материал лучше усваивается, когда происходит непосредственное общение преподавателя и студентов. Некоторые студенты испытывают трудности в том, чтобы задать вопрос преподавателю, попросить повторить информацию, если они ее недостаточно хорошо поняли или имели проблемы со связью. Они отметили, что изображение часто подтормаживало, и отставало от голосовой связи. Большому количеству студентов важен зрительный контакт с преподавателем и одногруппниками $(41 \%), 36 \%$ студентов ответили, что зрительный контакт никак не влияет на учебный процесс. Возможно, это объясняется тем, что студенты пятого курса хорошо знают друг друга, а для студентов младших курсов одобрение и обратная связь с их коллегами и преподавателями очень важна. Удивительно, что практически одинаковое количество студентов дали положительный и отрицательные ответы на вопрос о разнице в освоении онлайн гуманитарных и технических дисциплин. Студенты, давшие положительный ответ, отметили, что возникали сложности с графической частью урока (чертежами, схемами и т.п.). Несмотря на указанные 
сложности, большая часть студентов готова комбинировать онлайн и оффлайн обучение. Часть из них считает, что лекции могут проходить онлайн, а практические занятия оффлайн. Однако достаточно большое количество критически смотрят на онлайн-обучение и хотят отказаться от него полностью (31\%). Студенты отметили, что включение камер было вмешательством в личную жизнь, хотя все из них знали про функцию искусственного фона. Они возмущались, когда преподаватель требовал включить камеру. На наш взгляд, права и обязанности, взаимодействие преподавателей и студентов в процессе онлайн-обучения должны регламентироваться внутренними нормативными документами, что позволит преподавателю более четко предъявлять свои требования и пожелания. У студентов возникали вопросы обеспеченности онлайн-обучения программным обеспечением, организационной техникой, хотя НГТУ предлагал некоторые способы решения этих проблем. Что касается преподавателей, подобных проблем не возникало. Им было предложено работать из аудиторий кафедры, которые оснащены компьютерами и ноутбуками и стабильным интернет соединением. Работали компьютерные классы, в которых инженеры предлагали свою помощь при возникновении технических проблем. Большинство преподавателей проводили занятия из дома, лишь $2 \%$ ППС кафедры «Иностранные языки» проводили занятия из учебных корпусов. Коммуникация со студентами проходила также проходила по электронной почте, чаты - в Viber, WhatApp и Telegram. Текущий контроль знаний осуществлялся как в виде прямых ответов на вопросы преподавателя, так и с помощью тестирования.

\section{Список литературы}

1. Фоминых А.С. Смешанное обучение в вузе: институциональный, организационно-технологический и педагогический аспекты // Теория и практика общественного развития: сб.науч.тр. М., № 212014 С.272-278. 